\title{
KINETICS AND MECHANISM OF THE ELECTROCHEMICAL OXIDATION OF NITRITE ION DISSOLVED AS SODIUM NITRITE IN DIMETHYLSULPHOXIDE SOLUTIONS ON PLATINUM ELECTRODES*
}

\author{
J. A. Wargon and A. J. Arvita \\ División Electroquímica, Instituto Superior de Investigaciones, Facultad de Ciencias Exactas, \\ Universidad Nacional de La Plata, La Plata, Argentina
}

\begin{abstract}
The kinetics of the electrochemical oxidation of $\mathrm{NO}_{2}{ }^{-}$ion dissolved in DMSO has been studied on Pt electrodes at temperature ranging from 25 to $44^{\circ} \mathrm{C}$, by means of potentiostatic $E / I$ curves and by relaxation techniques.

The oxidation reaction is explained in terms of a consecutive reaction scheme which involves, as rate-determining step, nitrite-ion discharge on an adsorbed intermediate at the reaction interface, the latter apparently obeying a Langmuir isotherm.

Résumé-On a étudié la cinétique de la réaction électrochimique de l'ion $\mathrm{NO}_{2}^{-}$dissous dans du DMSO sur des anodes de $\mathrm{Pt}$ à des témperatures compris entre 25 et $44^{\circ} \mathrm{C}$. Les résultats furent obtenus avec des différentes techniques.

On a intérpreté ces résultats au moyen d'un mecanisme de réactions consécutifs comportant comme étape régulatrice une réaction du type ion plus radical adsorbée sur la surface de réaction.

Zusammenfassung-Es wurde die anodische Entladung von Nitrition am Platinelektroden in $\mathrm{NaNO}_{2}$ DMSO-Lösungen untersucht. Dabei wurde nach verschiedenen experimentellen Methoden vorgegangen.

Die Interpretation den experimentellen Ergebnissen wird ein Reaktionsmechanismus vorgeschlagen, bei dem die elektrochemische Reaktion von Nitrition mit einem adsorbierten Radikal des geschwindigkeitsbestimmende Schritt ist.
\end{abstract}

\section{INTRODUCTION}

THE STUDY of electrochemical reactions of different species dissolved in non-aqueous solvents such as DMSO is becoming of increasing interest, because it offers the possibility of systematically establishing the influence of solvent properties on those processes. As reported earlier, ${ }^{1}$ sodium nitrite dissolves easily in DMSO and exhibits the electrical conductance of a practically completely dissociated electrolyte.

The information published about the nitritc-ion/nitrogen-dioxide couple refers mainly to aqueous solutions ${ }^{2-5}$ and to sulphuric acid solutions. ${ }^{B}$ As far as DMSO solutions are concerned, the electrochemical reactions involving the nitrite-ion/ nitrogen-dioxide couple should occur within a potential range lower than that corresponding to the decomposition of the solvent.

In a previous paper the main anodic reaction products occurring on platinum electrodes and the kinetics of the anodic process under convective-diffusion control was considered. This sort of kinetic control was established at high positive potentials and it was characterized by an anodic limiting current which was very well defined, particularly at low nitrite-ion concentrations. At less positive potentials however, various facts, such as the independence of the $E / I$ curve on the rate of stirring, indicate an appreciable contribution of an activation overvoltage participating in the anodic process. The present paper contains a detailed study of the kinetics of the electrochemical reaction occurring at the electrochemical interface, which permits the establishment of the more likely mechanism of the anodic oxidation of nitrite ion in DMSO solutions.

* Manuscript received 1 January 1970. 


\section{EXPERIMENTAL TECHNIQUE}

The electrolysis cell and the platinum rotating disk electrode, as well as the purification of the solvent and the preparation of the solutions, were the same as those already described in previous publications. ${ }^{1.7}$ The apparent area of the working electrode was $7 \times 10^{-2} \mathrm{~cm}^{2}$.

The steady $E / I$ curves were measured by applying a constant potential at the working electrode and reading the current when the latter attained a constant value. Occasionally galvanostatic $E / I$ curves were also determined. Non-steady measurements were recorded, particularly overvoltage decay at current interruption. Experiments were carried out at temperatures comprised between 25 and $44^{\circ} \mathrm{C}$. The free surface of the electrolytic solution was flushed continuously with purified nitrogen during the experiments.

The nitrite-ion concentration was varied from $0.025 \mathrm{M}$ to $0.1 \mathrm{M}$, and $1 \mathrm{M}$ potassium perchlorate was added as supporting electrolyte. The rotation speed of the working electrode covered the range from 450 to $2200 \mathrm{rev} / \mathrm{min}$.

\section{RESULTS AND INTERPRETATION}

\section{Steady $\mathrm{E} / \mathrm{I}$ curves}

Figures 1 to 3 show typical sets of $E / I$ curves recorded at various rotation speeds after correction for the pseudo-ohmic polarization, for different sodium-nitrite concentrations and temperature.

These curves exhibit the following features (i) a large potential region referred to the initial rest potential, where practically no steady current flows (ii) a region of about $0 \cdot 1 \mathrm{~V}$ where the $E / I$ characteristics are independent of the rate of stirring (iii) an intermediate region where there is an effect of the rate of stirring (iv) the occurrence, at high anodic polarization, of a current plateau which depends linearly both on the square root of the rotation speed of the working electrode and also on the

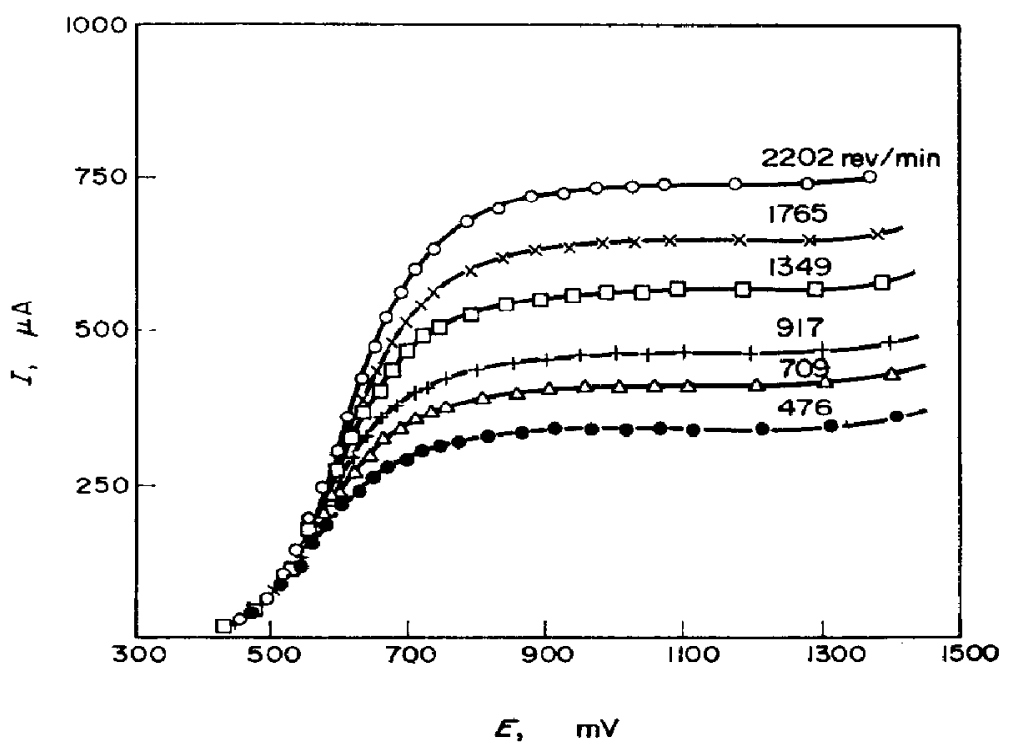

FIG. 1. $E / I$ curves obtained at different rotation speeds. $c^{0}, 0.04960 \mathrm{M} ; c_{\text {KClO }}, 1 \mathrm{M} ; 36^{\circ} \mathrm{C}$. 


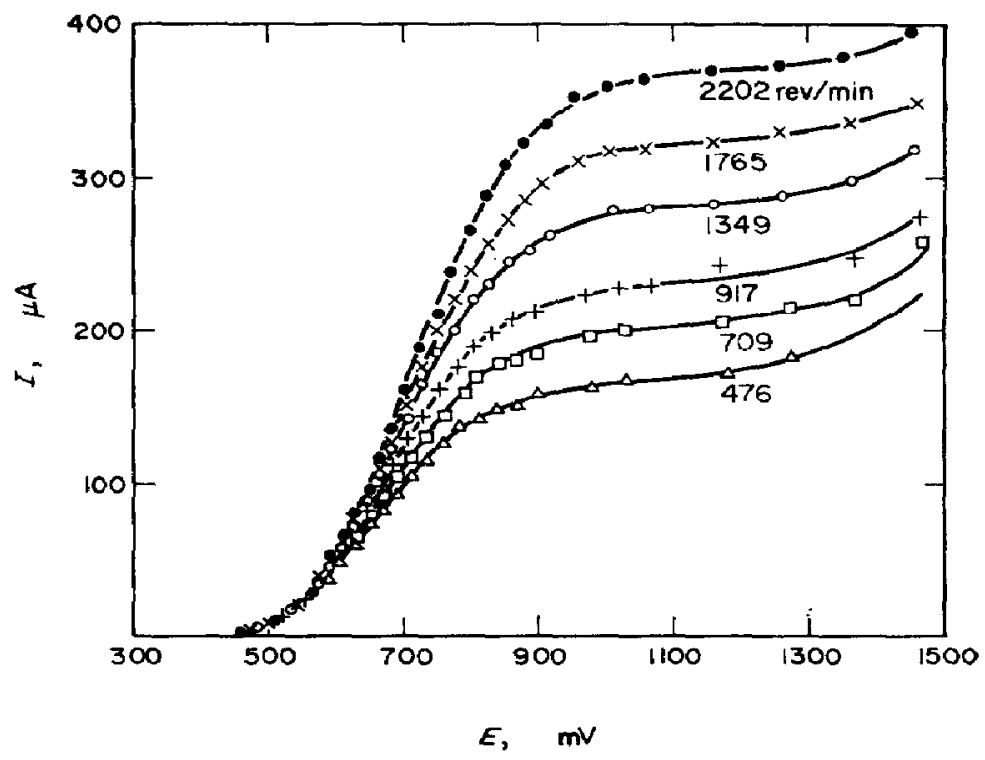

FIG. 2. $E / I$ curves obtained at different rotation speeds. $c^{0}, 0.02547 \mathrm{M} ; c_{\mathrm{KCjO}}, 1 \mathrm{M} ; 36^{\circ} \mathrm{C}$.

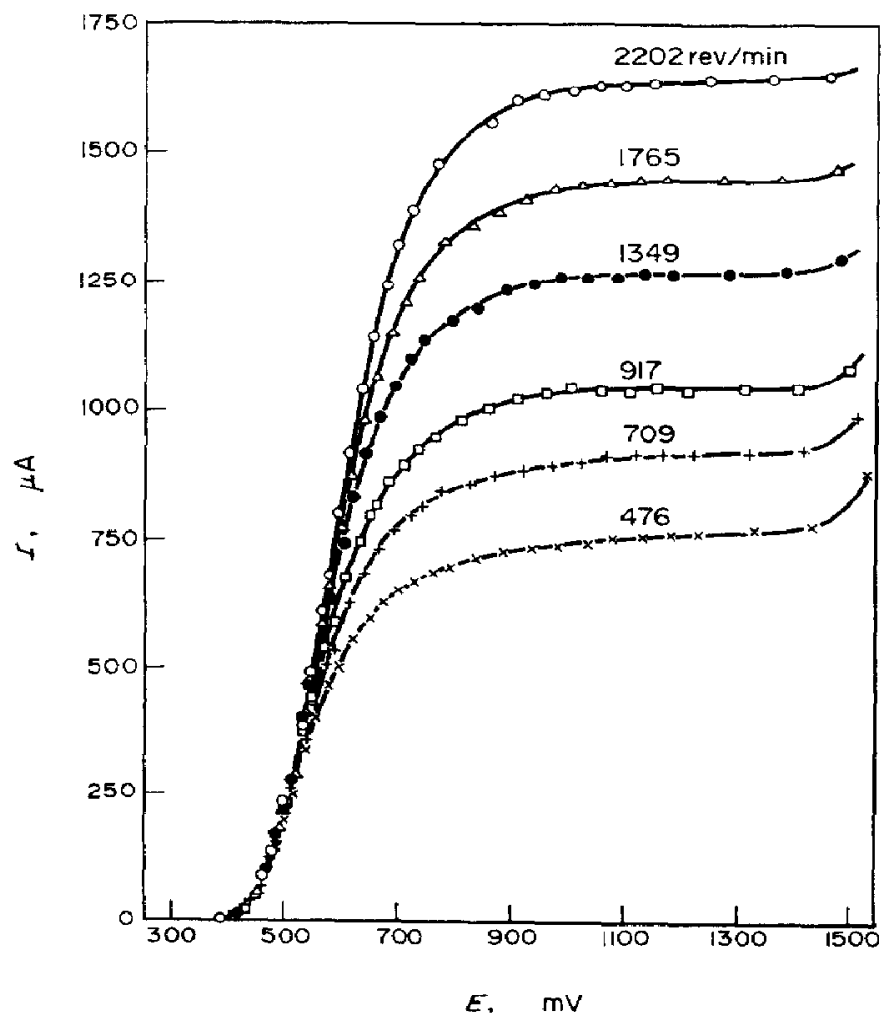

Fig. 3. $E / I$ curves obtained at different rotation speeds. $c^{0}, 0.09958 \mathrm{M}$; $c_{\mathrm{KClO}_{4}}, 1 \mathrm{M} ;{ }^{\circ} 44 \mathrm{C}$. 
nitrite-ion concentration. It corresponds to the anodic process under a net convectivediffusion control as already described. ${ }^{1}$ The $E / I$ curves exhibit no hysteresis, so corresponding to an electrode surface which attains a constant activity at each anodic potential. To establish the behaviour of the $E / I$ curves, plots of the potential $E$, against $\log \left[\left(I_{\mathrm{L}}-I\right) / I\right]$ were drawn, where $I_{\mathrm{L}}$ is the anodic limiting current. These plots, as shown in Fig. 4, present two straight line portions. At low potentials the

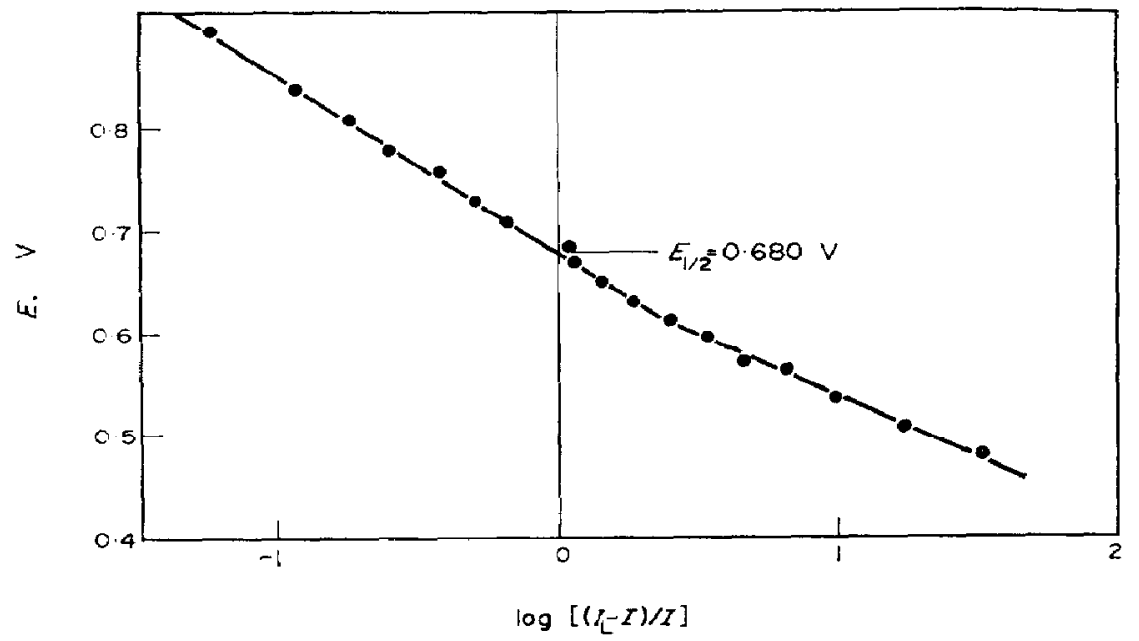

FIG. 4. Plot of $E v s \log \left[\left(I_{L}-I\right) / I\right]$.

$c^{0}, 0.02547 \mathrm{M} ; c_{\mathrm{KCOO}}, 1 \mathrm{M} ; \omega, 709 \mathrm{rpm} ; 36^{\circ} \mathrm{C}$.

slope of the straight line is closely equal to $0.120 \mathrm{~V}$, a figure which corresponds to the ratio $2 \cdot 3(2 R T / F)$ at the temperature of the experiments. This ratio results when the number of electrons per mole of reacting species participating in the electrode reaction, $n$, is 1 and the transfer coefficient assisting the anodic reaction, $\alpha$, is $0 \cdot 5$. In the neighbourhood of the half-wave potential, $E_{1 / 2}^{\mathbf{a}}$, the slope of the straight line approaches the value of $0.175 \mathrm{~V}$. This figure is reasonable if a convective-diffusion overvoltage also contributes at higher anodic polarizations. Thus, the slope of the theoretical straight line under the above mentioned conditions should be equal to $0 \cdot 180 \mathrm{~V}$ for the experiment shown in Fig. 4.

Let us consider now the dependence of the half-wave potential on the rate of stirring and the nitrite-ion concentration. Data assembled in Table 1 indicate that, at a fixed concentration, the half-wave potential increases as the rate of stirring

Table 1. Dependence of the anodic half-wave POTENTIAL ON STIRRING

$c^{0}, 0.02547 \mathrm{M} ; c_{\mathrm{KGlO}} 1 \mathrm{M} ; 36^{\circ} \mathrm{C}$

\begin{tabular}{|c|c|}
\hline $\begin{array}{c}\omega \\
\mathrm{rev} / \mathrm{min}\end{array}$ & $\underset{\mathbf{V}}{E_{1 / \mathbf{z}}^{\mathbf{a}}}$ \\
\hline $\begin{array}{r}476 \\
709 \\
917 \\
1349 \\
1765 \\
2202\end{array}$ & $\begin{array}{l}0.670 \\
0.685 \\
0.694 \\
0.703 \\
0.712 \\
0.723\end{array}$ \\
\hline
\end{tabular}


increases. This dependence is comprised in the definition of the half-wave potential for an irreversible electrochemical process controlled by a charge-transfer step.

Figure 5 illustrates the dependence of the current on the rotation speed at different anodic polarizations in the intermediate region of the $E / I$ curve. A net deviation from linearity is observed in the $I / \omega^{1 / 2}$ plots; at smaller polarization larger deviations are observed.

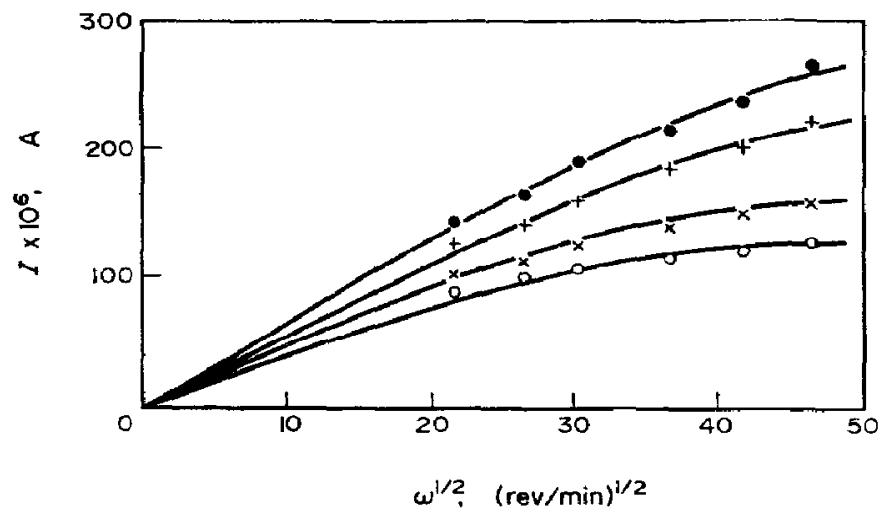

FIG. 5. Plot of $I v s \omega^{1 / 2}$.

$E=0.675 \mathrm{~V}(\mathrm{O}) ; 0.700 \mathrm{~V}(\times) ; 0.750 \mathrm{~V}(+) 0.800 \mathrm{~V}(\mathrm{O})$. $c^{0}, 0.02547 \mathrm{M}$; cKClO $_{4}, 1 \mathrm{M} ; 36^{\circ} \mathrm{C}$.

In order to eliminate the convective diffusion contribution to the electrochemical process, $E / I$ curves were processed according to the Frumkin-Teodoradse method for intermediate kinetics for a first-order reaction. Accordingly, plots of $1 / I$ against $1 / \omega^{1 / 2}$ were performed at various anodic polarizations, as shown in Figs. 6 to 8 for

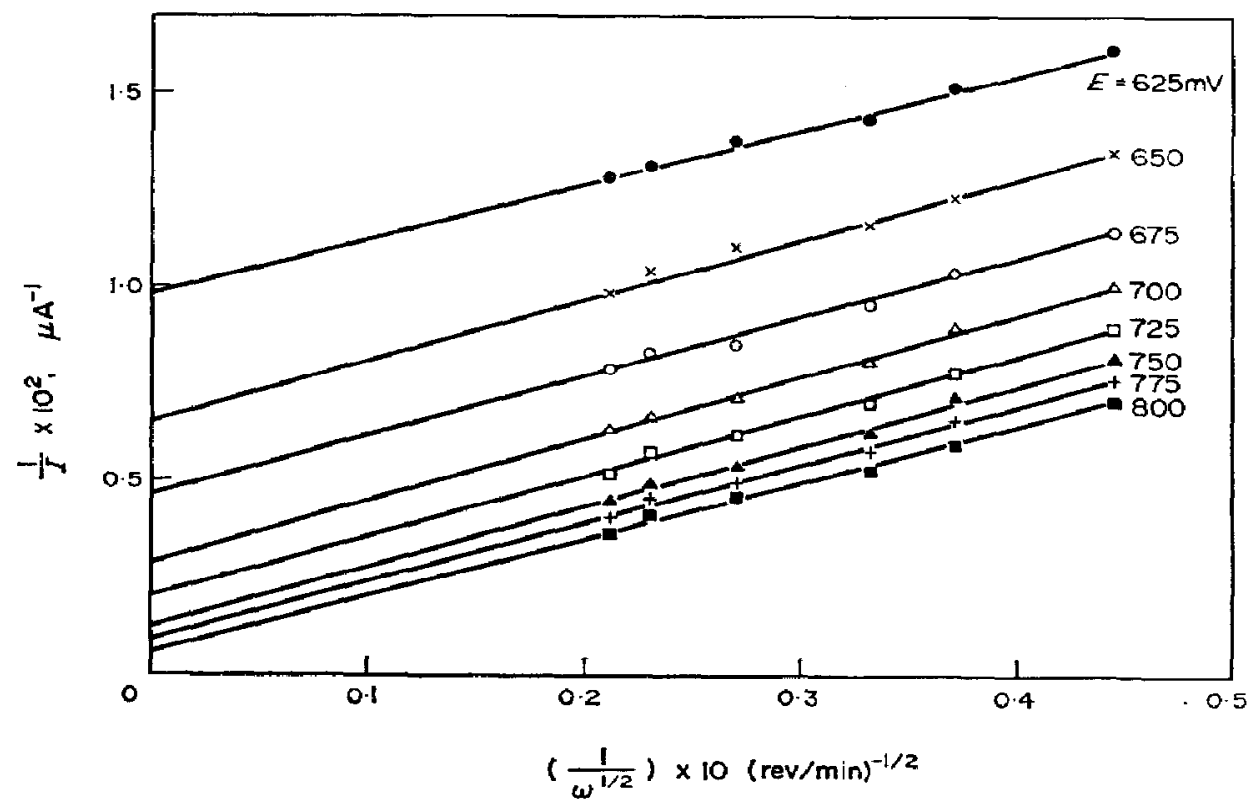

FIG. 6. Plot of $I^{-1}$ vs $\omega^{-1 / 2}$. $c^{0}, 0.02547 \mathrm{M}$; $c_{\mathrm{KClO}_{4}}, 1 \mathrm{M} ; 36^{\circ} \mathrm{C}$. 


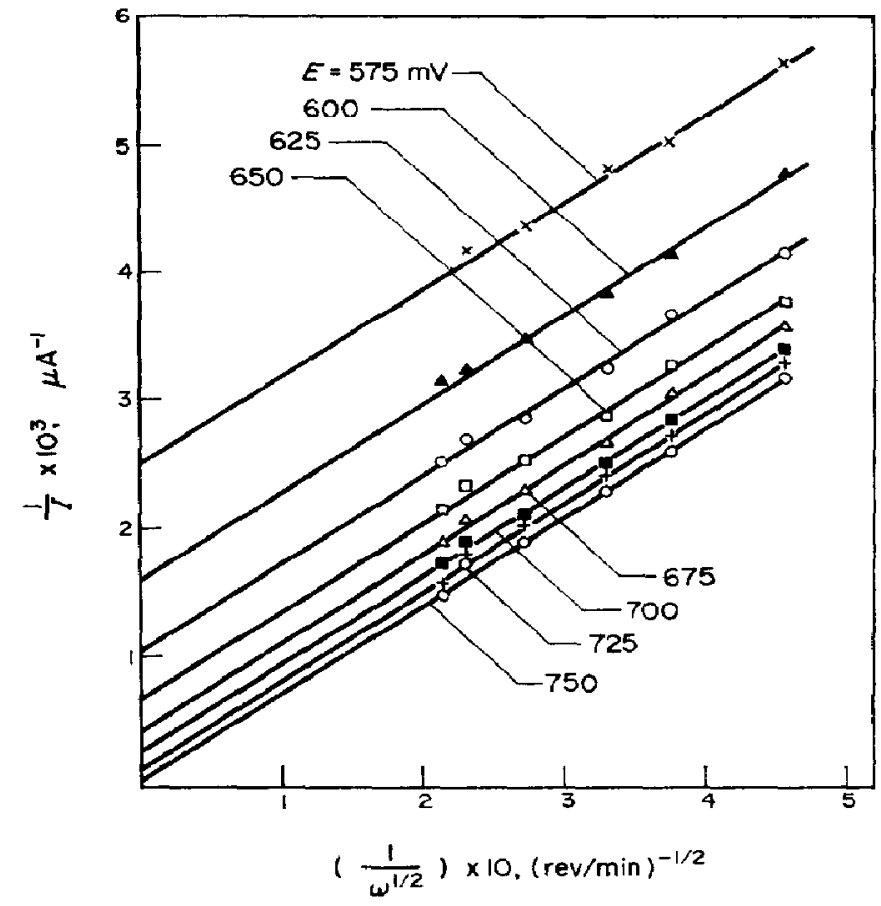

Fig. 7. Plot of $I^{-1}$ vs $\omega^{-1 / 2}$. $c^{0}, 0.04960 \mathrm{M} ; c_{\mathrm{KClO}}, 1 \mathrm{M} ; 36^{\circ} \mathrm{C}$.
FIG. 8. Plot of $I^{-1}$ vs $\omega^{-1 / 2}$ $c^{0}, 0.09994 \mathrm{M}$; ckc10_, $1 \mathrm{M} ; 25^{\circ} \mathrm{C}$.

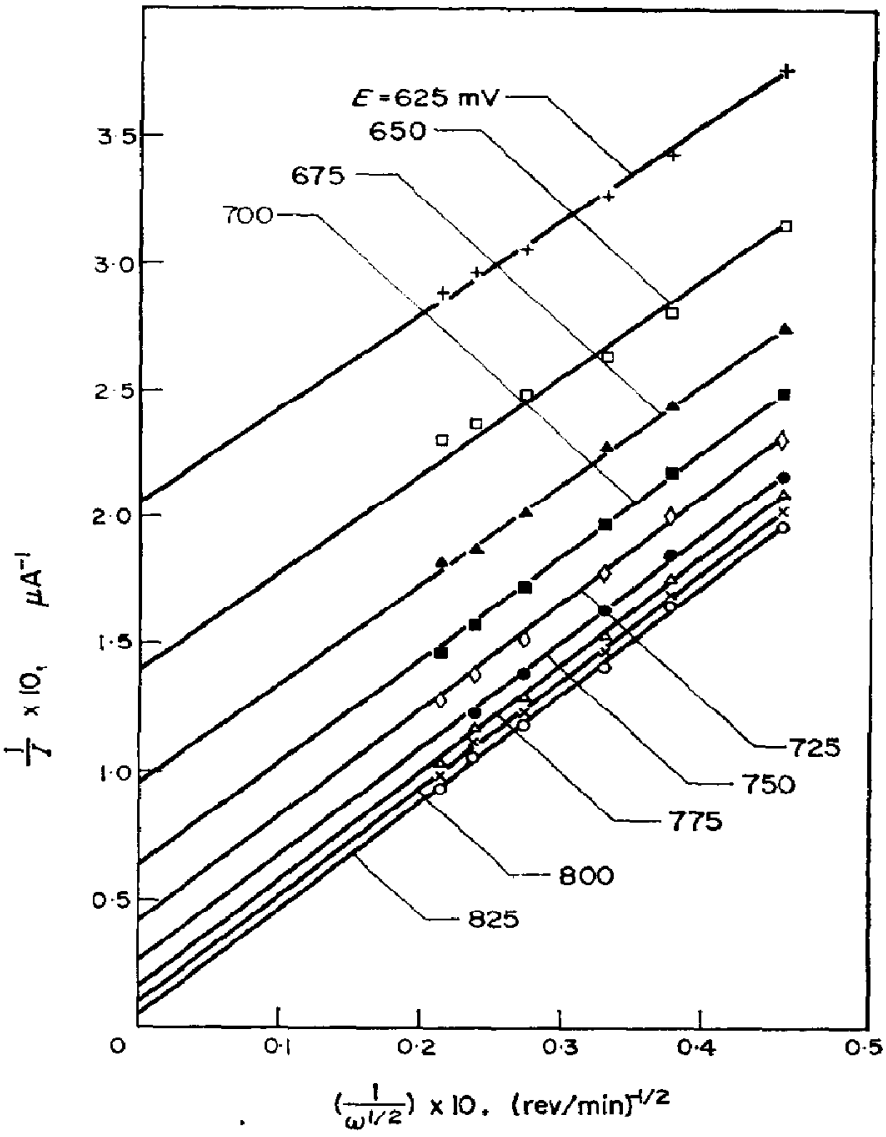


different experimental conditions. A set of good straight lines are obtained whose slopes can be calculated within 6 per cent with

$$
B_{\mathrm{i}}=0.62 z F D_{\mathrm{i}}^{2 / 3} \nu^{-1 / 6} \text {, }
$$

as shown in Table 2. $D_{1}$ is the experimental diffusion coefficient of nitrite ion in the employed solutions in $\mathrm{cm}^{2} / \mathrm{s}$, and $v$ is the kinematic viscosity in $\mathrm{cm}^{2} / \mathrm{s}$. Both magnitudes are known, as already reported in a previous publication. ${ }^{\mathrm{I}}$

TABLE 2. COMPARISON BETWEEN THEORETICAL AND EXPERIMENTAL SLOPES OBTAINED FROM THE (1/I) vs $\left(1 / \omega^{1 / 2}\right)$ PLOTS

\begin{tabular}{ccccc}
\hline$c^{0}$ & $\begin{array}{c}c_{\mathrm{KClO}_{\mathbf{L}}} \\
\mathrm{M}\end{array}$ & $\begin{array}{c}\text { Temp } \\
{ }^{\circ} \mathrm{C}\end{array}$ & $\begin{array}{c}\boldsymbol{B}_{\mathrm{i}} \\
(\mu \mathrm{A} / \mathrm{rev} / \mathrm{min})^{1 / 2}\end{array}$ & $\begin{array}{c}{\left[\mathrm{d}\left(I^{-1}\right) / \mathrm{d}\left(\omega^{-1 / 2}\right)\right]^{-1}} \\
\mu \mathrm{A} / \mathrm{rpm}^{1 / 2}\end{array}$ \\
\hline 0.09958 & 1 & 25 & 25 & 24 \\
0.09958 & 1 & 36 & 31 & 33 \\
0.09958 & 1 & 44 & 35 & 32 \\
0.04960 & 1 & 36 & $13 \cdot 5$ & $14 \cdot 3$ \\
0.02547 & 1 & 36 & 8 & $7 \cdot 7$ \\
\hline
\end{tabular}

The extrapolation of the straight lines to $\left(1 / \omega^{1 / 2}\right)=0$, as shown in Figs. 6 to 8 , yields the current related to the activated electrochemical reaction, which can be expressed in terms of a Tafel relationship, as seen in Figs. 9 and 10. The Tafel slopes, $b_{\mathrm{T}}$, derived from these plots are assembled in Table 3. The experimental Tafel slopes are close to $2 \cdot 3(2 R T / F)$. Table 3 also includes the cd extrapolated at the initial rest potential. These figures however involve an appreciable error, as deduced for instance from Fig. 11.

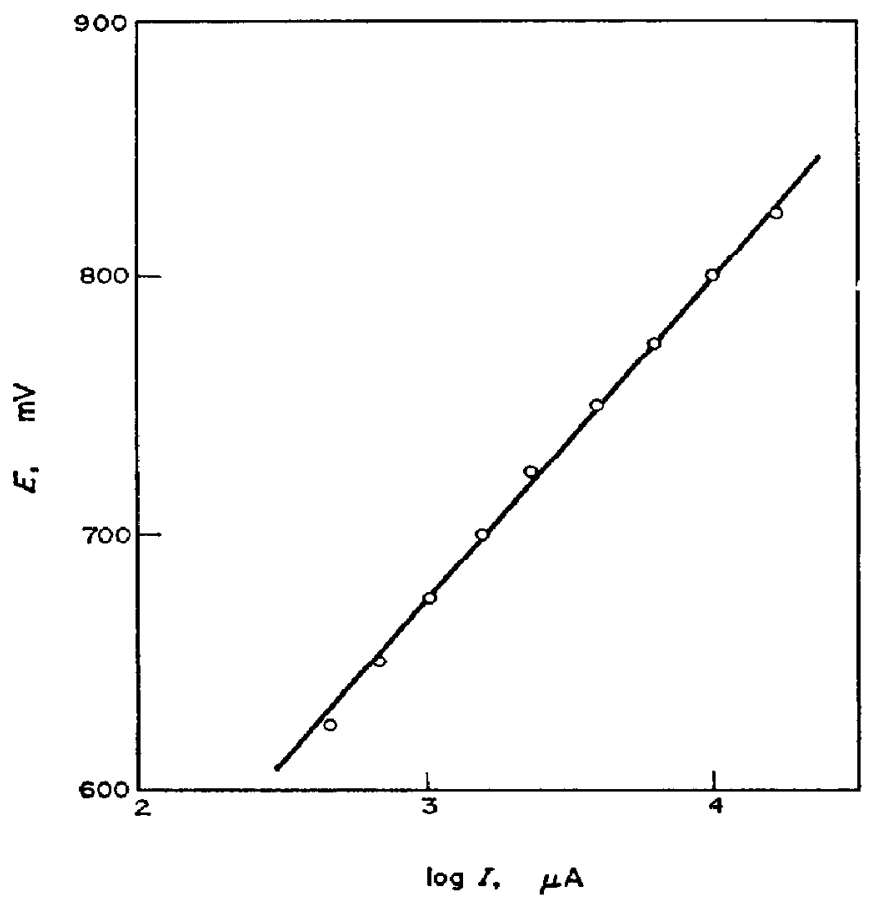

Fig. 9. $E / \log I$ plot obtained from extrapolation at $\omega \rightarrow \infty$. $c^{n}, 0.09994 \mathrm{M} ; c_{\mathrm{KClO}_{4}}, 1 \mathrm{M} ; 25^{\circ} \mathrm{C}$. 


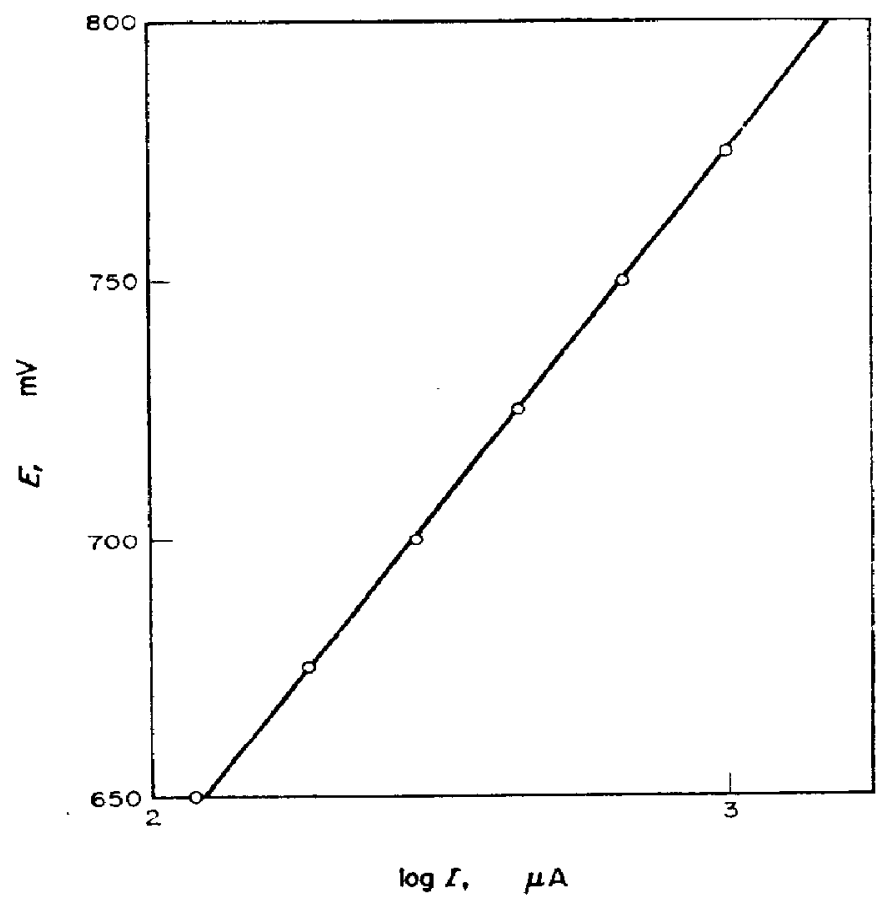

Fig. 10. $E / \log I$ plot obtained from extrapolation at $\omega \rightarrow \infty$. $c^{0}, 0.02547 \mathrm{M} ; c_{\mathrm{KClO}}, 1 \mathrm{M} ; 36^{\circ} \mathrm{C}$.

Table 3. Kinetic Parameters obtained from the TAfel plots

\begin{tabular}{|c|c|c|c|c|}
\hline $\begin{array}{l}c^{0} \\
\mathrm{M}\end{array}$ & $\underset{\mathbf{M}}{c_{\mathrm{KClO}}}$ & ${ }^{\text {I'emp }}$ & $\begin{array}{l}b_{\mathbf{T}} \\
\mathrm{V}\end{array}$ & $\begin{array}{l}\left(i_{0}\right)_{\text {app }} \\
\mathrm{A} / \mathrm{cm}^{2}\end{array}$ \\
\hline $\begin{array}{l}0.09994 \\
0.09958 \\
0.09994 \\
0.04960 \\
0.02547 \\
0.02547\end{array}$ & $\begin{array}{l}1 \\
1 \\
1 \\
1 \\
1 \\
1 \\
1\end{array}$ & $\begin{array}{l}25 \\
36 \\
44 \\
36 \\
36 \\
36\end{array}$ & $\begin{array}{l}0.126 \\
0.134 \\
0.134 \\
0 \cdot 118 \\
0.137 \\
0.137\end{array}$ & $\begin{array}{c}4.0 \times 10^{-8} \\
5.9 \times 10^{-7} \\
1.1 \times 10^{-8} \\
0.5 \times 10^{-8} \\
5.0 \times 10^{-8} \\
\left(5.0 \times 10^{-8}\right)^{*}\end{array}$ \\
\hline
\end{tabular}

* $E / I$ curve obtained by changing the potential downward.

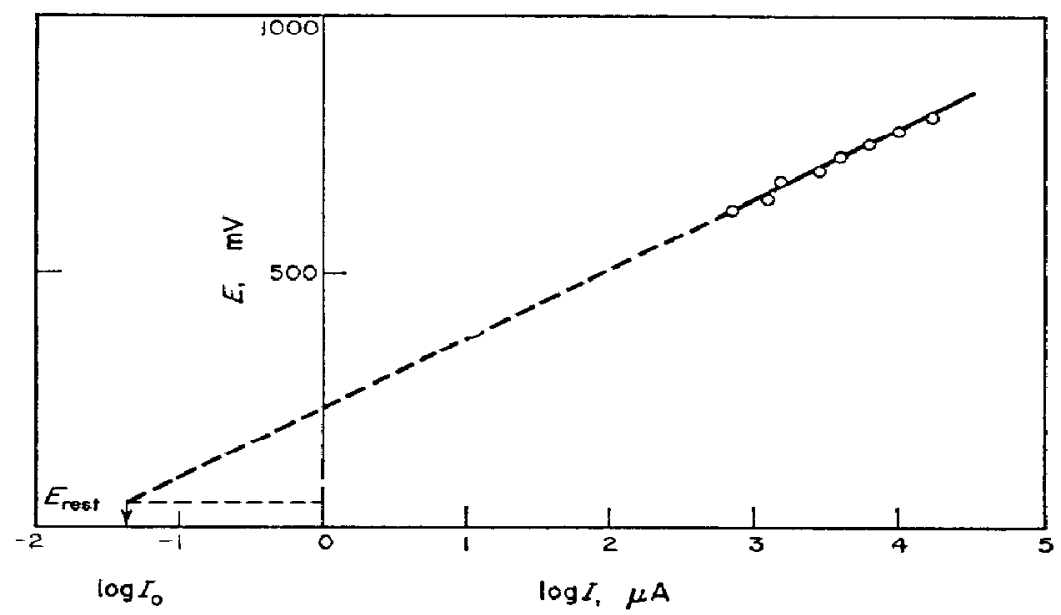

Fig. 11. Extrapolation of the $E / \log I$ plot to $E_{\text {rest. }}$ $c^{\circ}, 0.09958 \mathrm{M}$; CKClO $_{4}, 1 \mathrm{M}$; $36^{\circ} \mathrm{C}$. 
The rate of reaction increases with temperature according to an Arrhenius equation (Fig. 12), in the temperature range investigated. Within the potential range of 0.475 to $0.525 \mathrm{~V}$, the experimental activation energy is $16.5 \pm 1.0 \mathrm{kcal} / \mathrm{mol}$.

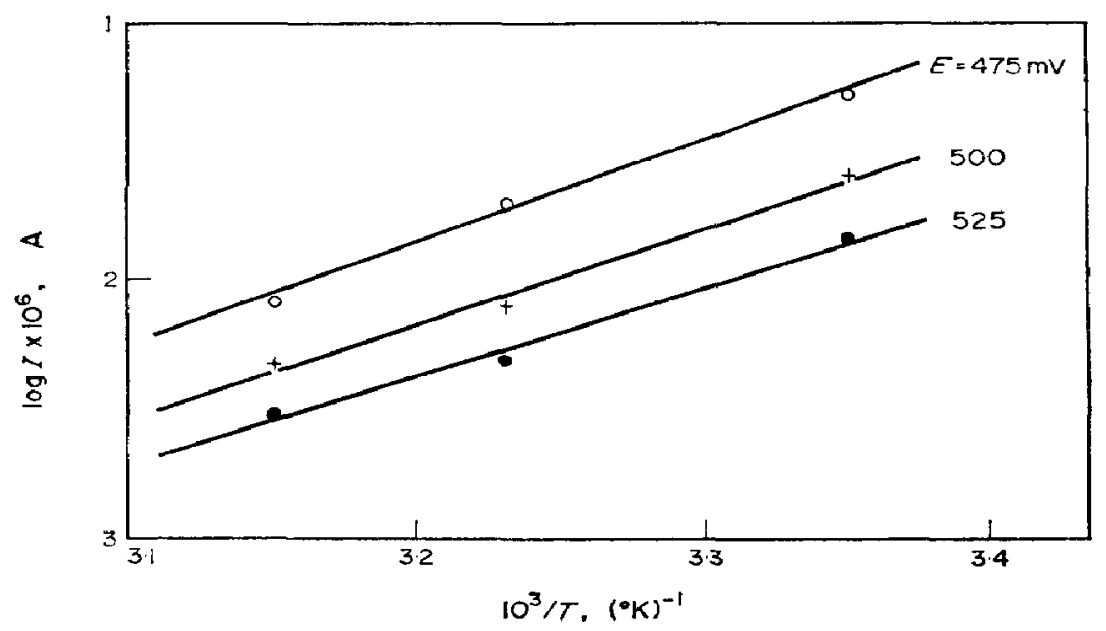

Fig. 12. Arrhenius plots at different anode potentials and constant rotation speeds. $c^{0}=0.09994 \mathrm{M} ; c_{\mathrm{KClO}_{4}}, 1 \mathrm{M} ; \omega=917 \mathrm{rev} / \mathrm{min}$.

2. Non-steady measurements

From the build-up of the anode potential, the electrode differential capacitance, $C_{T}$, at the initial potential was evaluated. Results are assembled in Table 4. The

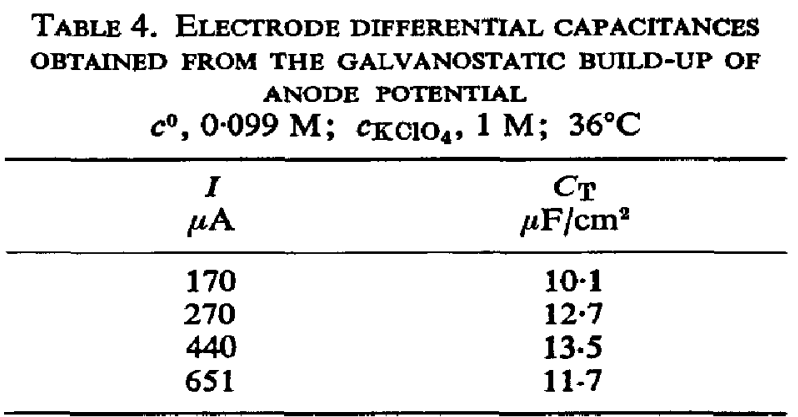

equations derived from the equivalent circuit representing the electrochemical double layer indicate that the pseudo-ohmic polarization must appear as a potential jump on the oscilloscope trace, which occurs in about $5 \times 10^{-9} \mathrm{~s}$, as is predicted from the $C_{\mathrm{g}} R_{\mathrm{s}}$ product, which in the present case is of the order of $10^{-10} \mathrm{~s} . C_{\mathrm{g}}$ and $R_{\mathrm{g}}$ represent the total capacitance and resistance which correspond to the pseudo-ohmic polarization. ${ }^{2}$ The pseudo-ohmic resistance varied between 90 and $130 \Omega$, depending on the electrode arrangement employed.

The decay of the anodic potential at current interruption was measured from $10^{-5}$ to $10 \mathrm{~s}$. These curves are semilogarithmically plotted in Fig. 13. They exhibit about 4-5 logarithmic decades of time where a linear relationship is in principle obeyed, although it should be recognized that there is some scatter of results, which becomes more evident when matching decay curves obtained at different sweep rates, after switching the current off at the same initial steady potential. 


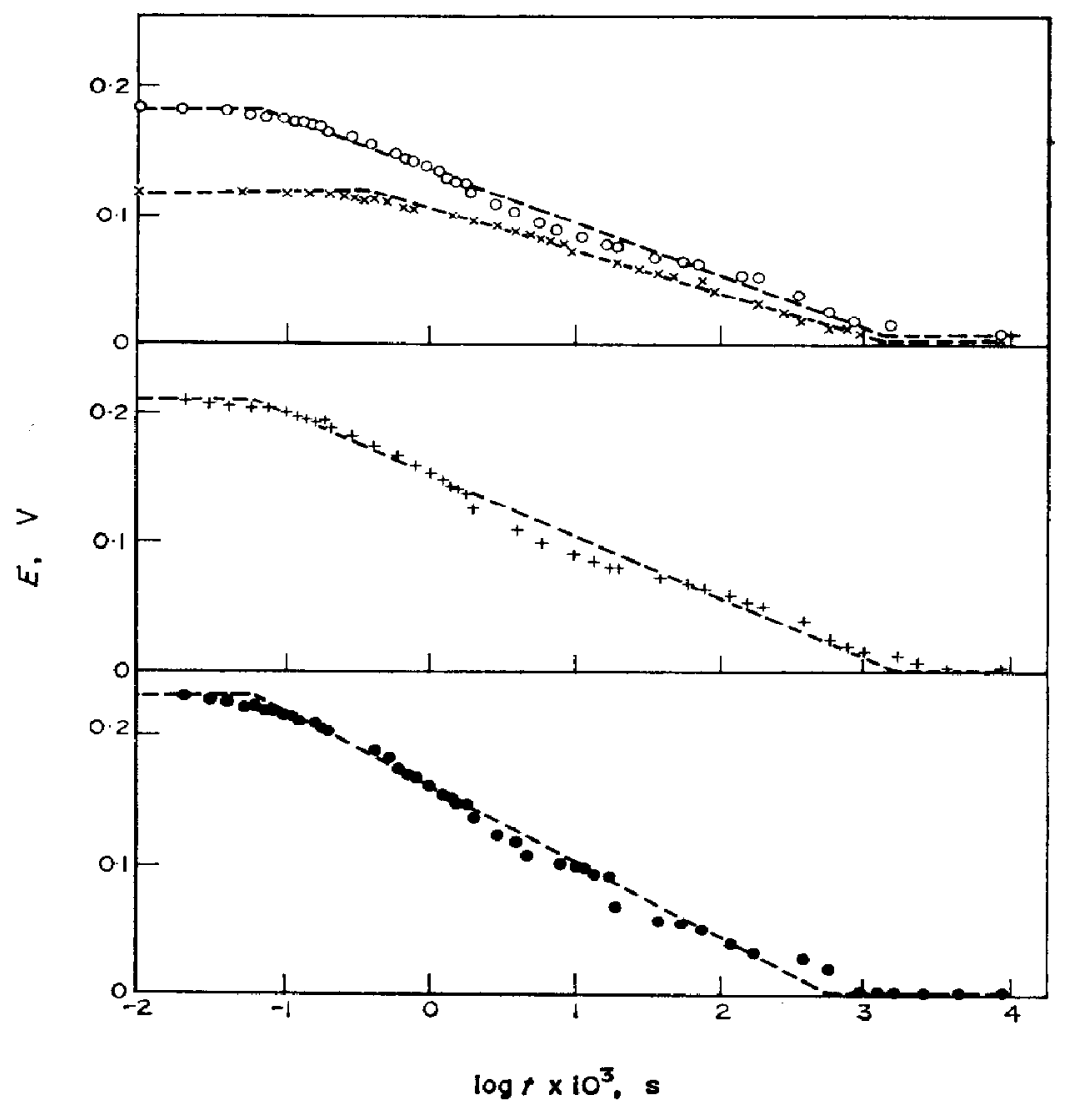

Fig. 13. $E / \log t$ plots obtained after current interruption.

$c^{0}, 0.09994 \mathrm{M}$; $c_{\text {KClO }}, 1 \mathrm{M} ; \omega, 917 \mathrm{rev} / \mathrm{min} ; 36^{\circ} \mathrm{C}$. O, 149; $\times, 43.4 ;+, 229$; $0,335 \mu \mathrm{A}$.

Kinetic parameters derived from the electrode potential decay such as the decay slope, $b_{\mathrm{d}}$, obtained from the $E / \log t$ plot, the apparent electrode differential capacitance, $C_{\mathrm{T}}$, at the initial potential and the apparent exchange cd $\left(i_{0}\right)_{\text {app }}$, are assembled in Table 5. To evaluate the latter the experimental $C_{\mathrm{a}}$ and $b_{\mathrm{d}}$ values were used.

The decay slopes are smaller than the Tafel slopes and the former increase as the initial potential increases. Their values are comprised between $2 \cdot 3(2 R T / 3 F)$ and $2 \cdot 3(R T / F)$. The $C_{\mathrm{a}}$ values are low and lie close to those reported from potential buildup curves. Finally the $\left(i_{0}\right)_{\text {app }}$ values are of the same order of magnitude as those obtained from the steady $E / I$ curves.

TABLE 5. KINETIC PARAMETERS DERIVED FROM THE ANODIC OVERVOLTAGE DECAY $c^{0}, 0.099 \mathrm{M} ; c_{\mathrm{KClO}}, 1 \mathrm{M} ; \omega=917 \mathrm{rev} / \mathrm{min} ; 36^{\circ} \mathrm{C}$

\begin{tabular}{cccc}
\hline $\begin{array}{c}I \\
\mu \mathrm{A}\end{array}$ & $\begin{array}{c}b_{\mathrm{d}} \\
\mathrm{V}\end{array}$ & $\begin{array}{c}C_{\mathrm{T}} \\
\mu \mathrm{F} / \mathrm{cm}^{2}\end{array}$ & $\begin{array}{c}\left(i_{0}\right)_{\mathbf{2 p p}} \\
\mathrm{A} / \mathrm{cm}^{2}\end{array}$ \\
\hline 43.4 & 0.034 & 16.8 & $8.1 \times 10^{-7}$ \\
149 & 0.042 & 8.4 & $4.6 \times 10^{-7}$ \\
229 & 0.046 & 8.5 & $4.7 \times 10^{-7}$ \\
335 & 0.058 & 11.4 & $1.4 \times 10^{-6}$ \\
\hline
\end{tabular}




\section{DIsCUSSION}

The results indicate that the electrochemical oxidation of nitrite dissolved in DMSO solution on platinum anodes is a one-electron per mole of anion process, and it comprises at least two main reactions, namely, the electrochemical oxidation of nitrite ion to nitrogen dioxide (dinitrogen tetroxide) and a further chemical reaction which involves the formation of the complex $\operatorname{DMSO}\left(\mathrm{N}_{2} \mathrm{O}_{4}\right){ }^{10}$

$$
\begin{aligned}
\mathrm{NO}_{2}- & =\mathrm{NO}_{2}+\mathrm{e}, \\
\left(2 \mathrm{NO}_{2}\right. & \left.=\mathrm{N}_{2} \mathrm{O}_{4}\right), \\
\text { DMSO }+\mathrm{N}_{2} \mathrm{O}_{4} & =\text { DMSO } . \mathrm{N}_{2} \mathrm{O}_{4}, \\
\text { DMSO } . \mathrm{N}_{2} \mathrm{O}_{4} & =\mathrm{DMSO}_{2}+\mathrm{N}_{2} \mathrm{O}_{3}, \\
\left(\mathrm{~N}_{2} \mathrm{O}_{3}\right. & \left.=\mathrm{NO}+\mathrm{NO}_{2}\right) .
\end{aligned}
$$

The complex undergoes a further oxidation, finally yielding $\mathrm{DMSO}_{2}$, and nitrogen oxides, mainly $\mathrm{NO}$ and $\mathrm{N}_{2} \mathrm{O}_{3}$, which partially dissolve in the solution. The identification of the dissolved nitrogen oxides, probably as adducts, has not been yet accomplished. The complexity of the system is revealed by the fact that when nitrogen dioxide is dissolved in DMSO, various different reactions take place and some of them extend over a long period, as deduced by the different charging plateaus observed when running cathodic $E / I$ curves on platinum rotating disk electrodes. ${ }^{11}$ However, in spite of this difficulty, the anodic electrochemical reaction can be envisaged according to a reaction scheme where there is an electron-transfer reaction followed by a chemical reaction. The latter however may consist of various reactions, probably both alternative and consecutive reactions, having rates of different order of magnitude.

For discussing the more likely reaction pathway it is reasonable to establish the behaviour of the platinum anode as a reacting surface. Since the highly oxidizing nitrogen dioxide is yielded by the nitrite-ion discharge and since the experimental electrode capacitance appears lower than that expected for a simple Helmholtz double layer, it seems that the platinum electrode surface acts under anodic polarization as a completely oxidized reaction surface, probably completely covered by an insoluble oxide film. Therefore the following mechanistic interpretation of the electrochemical oxidation of nitrite ion is based on the assumption that it occurs on a coated platinum electrode. Let us then consider the following consecutive reaction schemes.

Scheme I

$$
\begin{aligned}
\mathrm{NO}_{2}^{-}+\operatorname{Pt}(\mathrm{O}) & =\operatorname{Pt}(\mathrm{O}) \mathrm{NO}_{2}+\mathrm{e} \\
2 \mathrm{Pt}(\mathrm{O}) \mathrm{NO}_{2} & =\operatorname{Pt}(\mathrm{O})\left(\mathrm{N}_{2} \mathrm{O}_{4}\right)+\operatorname{Pt}(\mathrm{O}) \\
\operatorname{Pt}(\mathrm{O}) \mathrm{N}_{2} \mathrm{O}_{4}+\mathrm{DMSO} & =\operatorname{Pt}(\mathrm{O})+\mathrm{DMSO} . \mathrm{N}_{2} \mathrm{O}_{4} .
\end{aligned}
$$

From the kinetic standpoint any further chemical reactions taking place beyond the complex formation are, in principle, disregarded. 
Scheme II

Scheme III

$$
\begin{aligned}
\mathrm{NO}_{2}^{-}+\mathrm{Pt}(\mathrm{O}) & =\mathrm{Pt}(\mathrm{O}) \mathrm{NO}_{2}+\mathrm{e} \\
\operatorname{Pt}(\mathrm{O}) \mathrm{NO}_{2} & =\mathrm{NO}_{2}^{+}+\mathrm{Pt}(\mathrm{O})+\mathrm{e} \\
\mathrm{NO}_{2}++\mathrm{NO}_{2}^{-} & =2 \mathrm{NO}_{2} \\
\left(2 \mathrm{NO}_{2}\right. & \left.=\mathrm{N}_{2} \mathrm{O}_{4}\right) \\
\mathrm{N}_{2} \mathrm{O}_{4}+\mathrm{DMSO} & =\text { DMSO } \mathrm{N}_{2} \mathrm{O}_{4} .
\end{aligned}
$$

Schemes I, II and III include the participation of the $\mathrm{NO}_{2}$-intermediate on the electrode surface. Unfortunately its existence cannot be evidenced by any electrode pseudocapacitance as might be expected, probably because of an additional capacitance associated with the film layer on the electrode. The latter, as discussed further on, can mask the contribution of the pseudocapacitance. Therefore, the existence of the latter should be examined by means of the kinetic analysis of the postulated reaction paths, under the assumption of different adsorption isotherms for the reaction intermediates. The kinetic derivation may ignore any electrolyte concentration change at the electrochemical double layer, since results were obtained in the presence of an excess of potassium perchlorate, which is assumed to act only as supporting electrolyte.

Under these conditions, steps such as $I b$ and Ic or any subsequent chemical reaction should be discarded as rate-determining step. The Tafel slope $2 R T / F$ is consistent only with reaction Ia, (IIa), (IIIa), IIb or IIIb, the two latter under certain well-defined circumstances. Thus the Tafel slope alone implies that an electrontransfer step is rate-determining. Hence, arguments must be found in order to decide the more likely reaction path.

If reaction Ia, (IIa) or (IIIa) is rate determining, the rate of reaction, $v_{a}$, is given by

$$
v_{\mathrm{a}}=k_{\mathrm{a}} c^{\mathrm{s}}(1-X) \exp (\beta \eta F / R T),
$$

where $k_{\mathrm{a}}$ is a formal kinetic constant, $c^{\mathrm{\beta}}$ the concentration of the reacting anion at the electrode surface, $X$ the degree of surface coverage, $\beta$ the symmetry factor and $\eta$ the applied overpotential. If $\beta=0 \cdot 5$, (2) implies that $X \ll 1$, the Tafel slope is equal to $2 R T / F$ and, for concentrated solutions, there is a first-order dependence on nitrite-ion concentration, in agreement with the experimental results. There is, however, an important drawback to support reaction Ia as rate-determining. Since no dependence of $X$ on $\eta$ has been considered, one should expect that both Tafel and decay slopes be coincident, a circumstance which actually is not fulfilled. Therefore without further argument it is reasonable to discard also this reaction as rate-determining, and consequently mechanism $I$ as probable for the reaction.

Let us consider now reaction Irb as rate-determining. The rate equation, under Langmuir conditions, is

$$
v_{1 \mathrm{Ib}}=k_{\mathrm{IIb}} X \exp (\beta \eta F / R T)
$$


After assuming that the preceding reaction is in quasi-equilibrium, equation (3), for $X \rightarrow 0$,

$$
v_{\mathrm{IIb}}=k_{\mathrm{IIb}} K_{\mathrm{a}} c^{\mathrm{B}} \exp [(\beta+1) \eta F / R T],
$$

where $K_{\mathrm{a}}$ is the apparent equilibrium constant of step IIa. Equation (4) contains a Tafel slope of $2 R T / 3 F$ and first-order dependence on nitrite-ion concentration. For $X \rightarrow 1$, (3) gives:

$$
v_{\mathrm{IIb}}=k_{\mathrm{IIb}} \exp (\beta \eta F / R T) .
$$

Equation (5) involves a Tafel slope of $2 R T / F$ but the reaction order with respect to nitrite ion is zero.

The rate equation for the same reaction, under the assumption that the reaction intermediate follows a Temkin isotherm, is

$$
v_{\mathrm{IIb}}=k_{\mathrm{IIb}} X \exp (\beta \eta F / R T) \exp (\alpha f X) \approx k_{\mathrm{IIb}} \exp (\beta \eta F / R T) \exp (\alpha f X),
$$

where $f$ is the rate of change of the free energy of adsorption with degree of surface coverage and $\alpha$ is the fraction of adsorption energy assisting the anodic reaction. On assuming that step IIa is in quasi-equilibrium, (6) can be written

$$
v_{I I b}=k_{I I b} K_{\mathrm{a}}^{\alpha}\left(c^{\beta}\right)^{\alpha} \exp [(\alpha+\beta) \eta F / R T] .
$$

If $\alpha=\beta=0 \cdot 5$, (7) implies a Tafel slope of $R T / F$ and the reaction order with respect to nitrite ion is 0.5 . Consequently, under neither Langmuir nor Temkin isotherm conditions, does Scheme II with reaction IIb as rate-determining satisfy the experimental results.

Let us now examine the only possibility left, namely, step IIIb as rate-determining. Under Langmuir conditions the rate equation is

$$
v_{\text {IIIb }}=k_{\text {IIIb }} X c^{\mathrm{s}} \exp (\beta \eta F / R T) .
$$

For $X \rightarrow 0$, (8) yields a Tafel slope of $2 R T / 3 F$ and a reaction order of 2 . For $X \rightarrow 1$, it yields a Tafel slope of $2 R T / F$ and a reaction order of 1 . Under Temkin conditions, the rate equation is

$$
v_{\text {IIIb }}=k_{\text {IIIb }} c^{\mathrm{B}} \exp (\beta \eta F / R T) \exp (\alpha f X),
$$

which under the assumption that the preceding reaction is in quasi-equilibrium, becomes

$$
v_{\mathrm{IIIb}}=k_{\mathrm{IIIb}} K_{\mathrm{a}}^{\alpha}\left(c^{\mathrm{s}}\right)^{3 / 2} \exp (\eta F / R T) .
$$

This equation implies a Tafel slope of $R T / F$ and a reaction order with respect to nitrite ion of $3 / 2$.

The kinetic analysis of the various reaction schemes thus suggests that the most likely reaction pathway is expressed by scheme III involving step IIIb as ratedetermining and a large surface coverage by reaction intermediates, which obey a Langmuir adsorption isotherm. Some additional facts however must be given to support further the postulated reaction mechanism.

The mechanism must be consistent with the non-steady behaviour of the electrochemical system. In order to derive any reasonable conclusion from it the pseudocapacitance dependence on potential can be theoretically estimated. For the purpose let us assume, on the basis of experimental results, that at $0.475 \mathrm{~V}$, which corresponds 
to $43.4 \mu \mathrm{A}$, the lowest current used in anodic potential-decay runs, the degree of surface coverage is already larger than 0.5 , while in the potential range from 0.625 to $0.825 \mathrm{~V}$, where steady Tafel lines were drawn, it approaches unity. Taking $E=0.420 \mathrm{~V}$, $X=0.5$, the equilibrium constant $K_{\mathrm{a}}$ can be estimated. As Langmuir isotherm conditions apparently prevail for the adsorption of reaction intermediates, the corresponding electrode pseudocapacitance is ${ }^{12}$

$$
C_{\mathrm{s}}=\frac{k^{\prime} F}{R T}(1-X) X,
$$

where $k^{\prime}$ is the quantity of electricity required to cover the electrode surface with a monolayer. When $X=0.5$

$$
C_{\mathrm{s}}=\left(C_{\mathrm{s}}\right)_{\max }=\frac{k^{\prime} F}{4 R T} .
$$

If the partial reaction that generates the reaction intermediate is in quasi-equilibrium as already assumed for the anodic process, (11) can be expressed

or

$$
C_{\mathrm{s}}=\frac{k^{\prime} F}{R T} \frac{K_{\mathrm{a}} \exp (\eta F / R T) c^{0}}{\left[1+K_{\mathrm{a}} c^{0} \exp (\eta F / R T)\right]^{2}} .
$$

$$
K_{\mathrm{a}}{ }^{2}\left(c^{0}\right)^{2} \exp (2 \eta F / R T)-2 K_{\mathrm{a}} c^{0} \exp (\eta F / R T)+1=0 .
$$

By solving (14) we have

$$
\eta=-\frac{2 \cdot 3 R T}{F} \log K_{\mathrm{a}} c^{0}
$$

Accordingly, when $K_{\mathrm{a}} \approx 10^{-6}, E=0.420 \mathrm{~V}$ and $X=0.5$. With this value for $K_{\mathrm{a}}$ and taking $k^{\prime}=10^{15}$ particles $/ \mathrm{cm}^{2}$, the adsorption isotherm for the intermediate yields the $C_{\mathrm{B}} / E$ relationship. As shown in Fig. 14, within the potential range between 0.475 and $0.600 \mathrm{~V}, X$ is between 0.89 and 0.99 and it becomes practically one at $0.820 \mathrm{~V}$.

These results allow us to interpret the non-steady behaviour of the electrochemical reaction. Thus, at high degree of surface coverage, (13) can be approximated as

$$
C_{\mathrm{a}}=\frac{k^{\prime} F}{R T} K_{\mathrm{a}} \exp (-\eta F / R T)
$$

and, consequently, the decay slope is ${ }^{12}$

$$
b_{\mathrm{d}}=\left[b_{\mathrm{T}}(R T / F)\right] /\left[b_{\mathrm{T}}+(R T / F)\right] .
$$

Therefore, if $b_{\mathrm{T}}=2 R T / F$ one would expect $b_{\mathrm{d}}=2 R T / 3 F$, as actually occurs within the corresponding potential region.

Another comment is however necessary in order to understand why the apparent electrode differential capacitance is so different from the one predicted for $C_{8}$ at $X \approx 0.5$, which would be of the order of $1500 \mu \mathrm{F} / \mathrm{cm}^{2}$. Let us consider for the purpose the equivalent circuits illustrated in Fig. 15. $R_{1}$ represents the resistance of the first partial electrode reaction; $R_{2}$ corresponds to the resistance of the ratedetermining step; $R_{3}$ is the resistance of the film formed on the electrode; $C_{8}, C_{0}$ and $C_{\mathrm{d} 1}$ are respectively the capacitances due to the reaction intermediate, to the film 


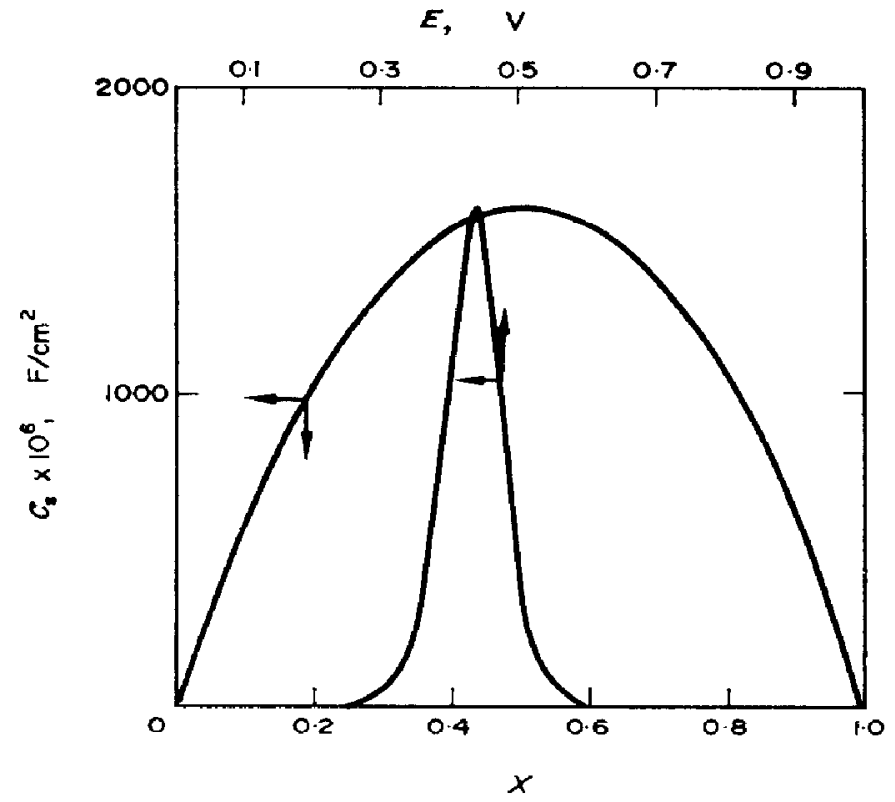

FIG. 14. $C_{\mathrm{B}} / E$ and $C_{\mathrm{B}} / X$ curves estimated as described in the text.

on the electrode surface and to the electrical double layer. For these circuits, the total capacitance, $C_{\mathrm{T}}$, which is actually measured, are given as

Equivalent circuit $\mathbf{I}$ :

$$
C_{\mathrm{T}}=C_{\mathrm{d} 1}+\frac{C_{\mathrm{s}} C_{\mathrm{o}}}{C_{0}+C_{\mathrm{s}}}
$$

I

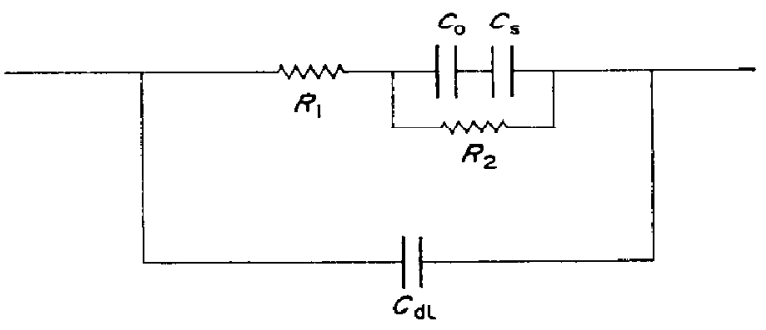

II

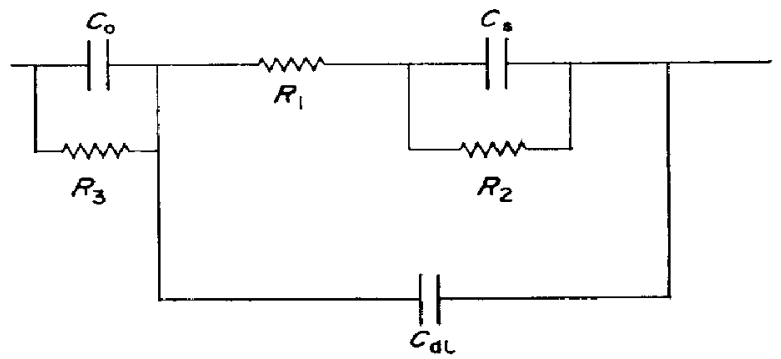

FIG. 15. Equivalent circuits employed for discussing the behaviour of the electrode reaction. 
Equivalent circuit II:

$$
C_{\mathbf{T}}=\frac{C_{0}\left(C_{\mathrm{s}}+C_{\mathrm{d}}\right)}{C_{\mathrm{B}}+C_{\mathrm{ad}}+C_{0}}
$$

According to (18), if $C_{\mathrm{B}}=1500 \mu \mathrm{F} / \mathrm{cm}^{2}$ and $C_{\mathrm{d} 1} \approx 10 \mu \mathrm{F} / \mathrm{cm}^{2}$, one would expect from the simple Helmholz double layer model the total electrode differential capacitance would be determined by $C_{\mathrm{d} 1}$ if $C_{0}$ is approximately equal to $1-2 \mu \mathrm{F} / \mathrm{cm}^{2}$. From the equivalent circuit II, if $C_{\mathrm{d} 1} \approx C_{0} \ll C_{\mathrm{g}}$, the total eletrode differential capacitance would be determined by $C_{0}$. Therefore, $C_{T}$ may be close to $C_{0}$ and a value for the latter of the order of $10 \mu \mathrm{F} / \mathrm{cm}^{2}$ is reasonable as has been already observed in various electrochemical reactions, particularly in melts ${ }^{13.14}$ where the reactions take place on oxidized electrode surfaces. The effect of the film is also revealed by the records of anodic decays, as the decay curves obtained for a set of experimental conditions and recorded within different interval, exhibit a constant potential shift of a few $\mathrm{mV}$. This shift of potential usually exceeds the experimental error and may occur either towards more positive or more negative values with respect to the average line.

Finally one should mention that no reliable cathodic process complementary to the anodic one can yet be detected with certainty, as the cathodic $E / I$ curve is complex and exhibits at least two cathodic waves whose location changes with time. With fresh solutions of $\mathrm{NO}_{2}$ in DMSO in the presence of the supporting electrolyte, the potential where the cathodic processes start is shifted about $0.759 \mathrm{~V}$ more negative than the initial rest potential. This may be considered as an additional argument related to the relatively marked irreversibility of the anodic reaction. Hence the foregoing discussion is consistent with the reaction mechanism postulated for the oxidation of the nitrite ion dissolved in DMSO solutions, on platinum electrodes.

Acknowledgement-The present work was partially supported with funds given by the Consejo Nacional de Investigaciones Cientificas y Técnicas of Argentina. One of us (J. A. Wargon) acknowledges the Consejo Nacional de Investigaciones Científicas y Técnicas for the fellowship granted.

\section{REFERENCES}

1. J. A. Wargon and A. J. Arví, Electrochim. Acta 16, 1619 (1971).

2. K. J. VetTER, Z. phys. Chem. 194, 199 (1950).

3. N. TANAKA and K. Kato, Bull. Chem. Soc. Japan 29, 837 (1956).

4. Yu. S. Lyalikov and O. M. Mukhamendnazarova, Izv. Akad. Nauk. Turkm. S.S.R. Ser. Fiz. Tekn, Khim. i Geol. Nauk, 45 (1963).

5. L. E. TOPOL, R. A. Osteryoung and J. H. Christie, J. electrochem. Soc. 112, 861 (1965).

6. E. JulizN and M. Comtat, Rev. Chim. Minérale 6, 885 (1969).

7. J. A. Ot abe and A. J. ARviA, Electrochim. Acta 14, 785 (1969).

8. A. FrumkIN and G. TeOdoradse, Z. Elektrochem. 62, 251 (1958).

9. K. J. VeTTER, Elektrochemische Kinetik. Springer, Berlin (1961).

10. C. C. AdDIson, Chemistry in Liquid Dinitrogen Tetroxide in Chemistry in Nonaqueous Ionizing Solvents, p. 26. Pergamon Press, Oxford, (1967).

11. J. A. Wargon and A. J. Arvía, to be published.

12. B. E. Conway, Theory and Principles of Electrode Processes. Ronald Press, New York (1965).

13. R. Casino, J. J. Podestí and A. J. ARvia, Electrochim. Acta 16, 121 (1971).

14. A. J. Arvía, J. J. Podestá and R. C. V. Piatt, Electrochim. Acta, 16, 1797 (1971). 